\title{
¿“CELTAS” EN ANDALUCÍA? MIRADA HISTORIOGRÁFICA SOBRE UNA PROBLEMÁTICA (CASI) OLVIDADA
}

\section{“CELTS" IN ANDALUSIA? A HISTORIOGRAPHICAL LOOK ON AN (ALMOST) FORGOTTEN ISSUE}

\author{
MANUEL ALBERTO FERNÁNDEZ GÖTZ*
}

\begin{abstract}
Resumen: La presencia de poblaciones célticas en el sur de la Península Ibérica es un hecho generalmente aceptado desde los inicios de las modernas investigaciones lingüísticas y arqueológicas, si bien su interpretación ha variado notablemente a lo largo del tiempo. En este trabajo se pretende realizar una aproximación historiográfica a esta interesante, pero indudablemente compleja, problemática. A través de un análisis diacrónico se mostrará cómo ha variado la importancia atribuida al elemento celta en la Protohistoria meridional, y cómo en la actualidad éste, si bien no es negado, se encuentra prácticamente ausente de las agendas investigadoras.
\end{abstract}

Palabras clave: Andalucía, Edad del Hierro, Celtas, Historiografía

\section{INTRODUCCIÓN}

El objetivo del presente trabajo es llamar la atención sobre una problemática actualmente casi ausente de la agenda investigadora de la Edad del Hierro de la Península Ibérica: la debatida presencia "céltica" en la zona meridional, fundamentalmente en tierras de la actual Andalucía. Para ello se ha acometido el intento de sintetizar las principales aproximaciones realizadas sobre la temática. Aunque a buen seguro no se recogen la totalidad de los autores y publicaciones que en un momento dado han tratado esta cuestión, sí se ha intentado

\footnotetext{
* Becario F.P.U. del MICINN, adscrito al Departamento de Prehistoria de la Universidad Complutense de Madrid (AP 2006-00598). mafernandez@ghis.ucm.es
}

\begin{abstract}
The presence of celtic populations in the south of the Iberian Peninsula is a fact which has generally been accepted since the beginnings of modern linguistic and archaeological investigations. However, ideas and interpretations have varied notably. This work aims to carry out a historiographic approximation of this interesting but also undoubtedly complex problem. Through a diachronic analysis it will be shown how the importance attributed to the celtic element in the southern protohistory has varied. It will also be demonstrated how at present this issue, even though not denied, is practically absent from the research agendas.
\end{abstract}

Key words: Andalusia, Iron Age, Celts, Historiography

seleccionar los trabajos considerados más significativos para mostrar la evolución historiográfica de la misma.

Por motivos operativos se ha establecido una división de los distintos autores en cuatro grandes etapas, que aunque en ocasiones puedan resultar arbitrarias, sobre todo en lo referente a la atribución de algunos autores a una u otra, pretenden obedecer no sólo a criterios cronológicos, sino también a la forma en que se ha enfocado la problemática de la presencia "céltica" en el sur de la Península Ibérica.

Antes de comenzar es necesario realizar dos puntualizaciones. En primer lugar, señalar que hemos dejado conscientemente en un segundo plano el ámbito de la Beturia céltica, debido a que el gran desarrollo que ha experimentado su investigación durante las dos últimas décadas (Berrocal Rangel 1992) permite 
disponer ya de una visión renovada de la problemática en esta región.

La segunda puntualización hace referencia al controvertido concepto de "celtas". Actualmente sabemos que, lejos de las visiones simplistas y monolíticas durante mucho tiempo asumidas, el constructo moderno de "celtas" resulta polisémico, siendo empleado con distintas acepciones (Ruiz Zapatero 1993 y 2001). Dicho esto, cuando en el texto se empleen los términos "celtas", "céltico" o "indoeuropeo" se hará siguiendo la terminología usada por los autores analizados, teniendo siempre en cuenta que nuestra concepción personal sigue la línea de los estudios que vienen desarrollando autores como G. Ruiz Zapatero. Así, y pese a que no rechazamos el uso de las palabras "céltico" y "celta", preferiblemente entre comillas, lo que sí consideramos inapropiado es hablar de "los celtas" en un sentido genérico como si de un grupo étnico se tratara (González Ruibal 2005).

\section{LOS INICIOS DE LA INVESTIGACIÓN: ERUDICIÓN HISTÓRICA Y ESTUDIOS LINGÜÍSTICOS}

La primera etapa que hemos establecido abarca básicamente los trabajos anteriores a la consolidación en España de la arqueología como disciplina científica. Aunque esta clasificación incluye una gran diversidad de autores, desde las obras de eruditos locales como Rodrigo Caro (1634) o Pérez Quintero (1794) hasta los estudios de grandes lingüistas como von Humboldt (1821), consideramos que existen algunas características comunes que definen a este primer periodo, destacando el interés por identificar a través de inscripciones en epígrafes y monedas ciudades citadas en las fuentes clásicas. Esta historia basada en los textos clásicos, junto a las aportaciones cada vez más importantes de la lingüística, conformará la visión que se tendrá sobre los celtas peninsulares hasta finales del siglo XIX.

Las referencias a una presencia céltica en el sur peninsular, basadas en la lectura de autores de la Antigüedad como Estrabón o Plinio, se encuentran ya presentes en las obras de eruditos de la Edad Moderna. Así, en el siglo XVII R. Caro (1634) dedicó un apartado de su libro sobre antigüedades de la ciudad de Sevilla y su convento a los pueblos célticos, señalando que parte de ellos se asentó en la Bética. Ya a finales del siglo XVIII, la obra de M. I. Pérez Quintero La Beturia vindicada (1794) constituía una auténtica reivindicación de un marco geográfico tradicionalmente descuidado por la erudición histórica. En ella, el autor persiguió un doble objetivo: a una escala más amplia, estudiar las antigüedades de célticos y túrdulos, algo poco corriente en una época en la que el interés se centraba principalmente en el período clásico romano; y a un nivel más local, identificar su villa natal de Trigueros con la antigua ciudad de Conistorgis.

En el siglo XIX, el desarrollo de los trabajos lingüísticos permitió ir definiendo la presencia "celta" en la Península Ibérica. En este sentido, resultó fundamental la aportación de W. von Humboldt (1821), quien fue capaz de identificar topónimos celtas provenientes de las fuentes literarias; posteriormente, los trabajos de E. Hübner (1893) contribuirían a incrementar notablemente el corpus de nombres conocidos a través de la epigrafía. En relación con nuestra temática, si bien von Humboldt considera que entre la línea formada por los nombres terminados en -briga y los Pirineos y el Mediterráneo no se habrían producido penetraciones celtas importantes, por otro lado acepta que algunos puntos aislados en la Bética, como Ebura y Celti, pudieron llegar a ser célticos. Otro estudio, muy poco conocido en España, es el del geógrafo y cartógrafo H. Kiepert (1865), quien realizó una aproximación a la etnografía antigua de la Península Ibérica a partir de las evidencias textuales y lingüísticas. Aunque admite la presencia céltica entre el Guadiana y el Tajo, considera que la "conquista" celta de la Península no pudo extenderse por sus llanuras orientales y meridionales.

Como ya se ha indicado, una de las principales inquietudes en esta etapa era la identificación de ciudades citadas por los textos de los escritores de la Antigüedad. En esta línea hay que enmarcar también el estudio realizado por el padre F. Fita (1897), quien abordó la problemática, recientemente retomada por Pascual Barea (2004), de los Callenses, considerados célticos por Plinio. Basándose en el descubrimiento de una inscripción, Fita situó el municipium Callense en Moguerejo, afirmando que los Callenses no eran los mismos que los de la ciudad de Callet.

Finalmente, y antes de concluir el análisis de esta primera etapa de la investigación, es necesario hacer referencia a un fenómeno que tradicionalmente se vinculó a los celtas en numerosas regiones europeas: el megalitismo. En este sentido, Andalucía no constituyó una excepción (Mitjana 1847; Murguía 1858), aunque ya en 1868 M. Góngora y Martínez rechazó la asociación megalitos-celtas en el antiguo reino de Granada, región objeto de su estudio. Siguiendo las fuentes antiguas, concluyó que esta región no fue ocupada por los celtas, desvaneciéndose así la atribución a ellos de los megalitos: [...] ha sido preciso renunciar a una atribución tan exclusiva, y convenir en que los monumentos 
megaliticos han podido pertenecer a distintas gentes $y$ a épocas muy diversas, algunas de las cuales se escapan a la sagacidad de la historia (Góngora y Martínez 1868: 124-125; Maier 1999a: 101).

\section{LA ÉPOCA DE LOS GRANDES PIONEROS}

La segunda etapa de la investigación está marcada sobre todo por la labor de dos de los "pioneros" de la arqueología en España, Bonsor y Siret. Durante este periodo, la "historia filológica" de los eruditos se fue transformando, progresivamente, en arqueología, si bien en ocasiones el resultado fue una amalgama de arqueología y filología históricas.

Antes de pasar a analizar la labor de estas dos grandes figuras es necesario mencionar el influyente trabajo de H. d'Arbois de Jubainville "Les Celtes en Espagne" (1893-94). Su estudio, basado en los escritores clásicos y la toponimia, contiene un apartado en el que analiza la presencia celta en el sur peninsular, incluyendo tanto a los célticos de la Beturia como a los que aparecen citados por los textos al este del río Guadalquivir, y también a los celtíberos que se habrían establecido en Andalucía oriental. De este modo, abordó una cuestión muy controvertida hasta la actualidad: la situación de las localidades de Munda y Certima, que él sitúa en Andalucía, y con ellas el ataque de Graco a la que denomina ultima Celtiberiae. Esta interpretación ha sido recientemente retomada por A. Capalvo (1996), como veremos más adelante.

Todos los estudios vistos hasta ahora se habían basado fundamentalmente en la información de las fuentes clásicas y la lingüística. Sería J. Bonsor, auténtico pionero de la arqueología en el suroeste, cuya figura ha sido objeto de un ejemplar estudio por parte de J. Maier (1999a y 1999b), el primer autor en establecer una relación entre restos arqueológicos y presencia celta en el Bajo Guadalquivir (Bonsor 1899). Siguiendo los textos de geógrafos e historiadores greco-latinos, Bonsor siempre aceptó la presencia de un componente celta entre las poblaciones del Bajo Guadalquivir, si bien su identificación arqueológica, que creyó detectar en el registro de Los Alcores (Fig. 1), fue variando a lo largo del tiempo. De acuerdo con la mentalidad de la época, consideró que las alteraciones en el registro arqueológico se debían o conllevaban la presencia de un cambio étnico. En su esquema, que relacionaba artefactos arqueológicos con datos históricos transmitidos por las fuentes escritas, la invasión celta constituía uno de los principales hitos, al igual que la fundación de Gadir por los tirios o la llegada de griegos a Tartessos (Maier 1999a: 123-124).
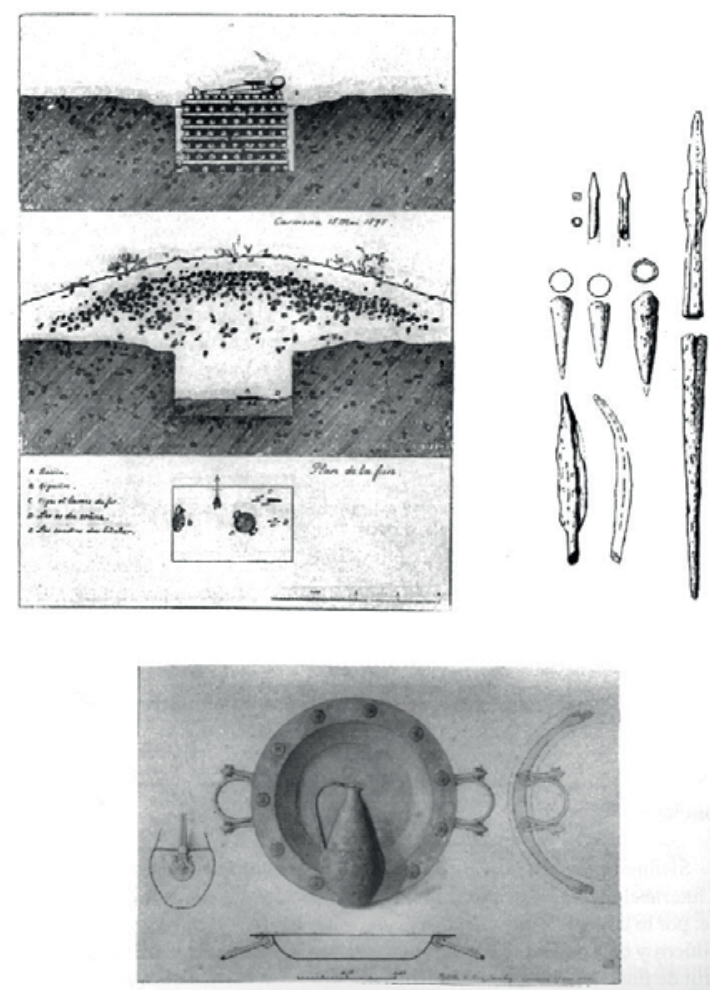

Figura 1. Túmulo de la Cañada de Ruiz Sánchez (Carmona), Jorge Bonsor (según Maier 2007)

En un primer momento, Bonsor atribuyó a la invasión céltica de Andalucía la cerámica campaniforme que encontró durante sus excavaciones en El Acebuchal (Carmona), afirmación que, gracias a las indicaciones de Flinders Petrie, desecharía años después a favor de una datación en el Neolítico (Maier 1999a: 123-124).

Por ello, trató de encontrar nuevas pruebas arqueológicas de la invasión céltica, que intentó obtener en un principio en Portugal, ya que los lusitanos eran considerados de origen celta. Prueba de ello fue la relación epistolar que mantuvo con el arqueólogo portugués Antonio Dos Santos Rocha (Maier 1999a: 196; 1999b).

En cualquier caso, Bonsor optó por acuñar el término "celto-púnico" para relacionar la presencia celta, documentada por los textos, con el registro arqueológico. En la necrópolis de la Cruz del Negro (Carmona) distinguió dos grupos de materiales, unos de ascendencia púnica y otros indígenas, atribuyendo éstos últimos a la invasión celta. De este modo, Bonsor calificó las necrópolis tipo Cruz del Negro, que sitúa entre el siglo VI y el III a. C., como celto-púnicas (Maier 1999a: 196 y 226). 
Por estas fechas hay que señalar también la influencia del trabajo de J. Déchelette (1908), quien afirmaba que los túmulos de Los Alcores eran totalmente celtas, calificando de importaciones los materiales fenicios aparecidos en estas tumbas. Su interpretación se basaba en considerar el rito de la incineración propio de los celtas y no de los fenicios (Maier 1999a: 226).

Bonsor, aunque en principio no muy de acuerdo con estas teorías, consideró de gran importancia el trabajo de Déchelette, como queda de manifiesto en la correspondencia que mantuvo con Huntington y Siret (Maier 1999b). Tras la visita de Siret a Bonsor en Mairena en 1910, éste último decidió distinguir lo fenicio de lo púnico, terminando con la ambigüedad con la que eran empleados estos términos. Así, Bonsor clasificó los túmulos como celto-fenicios en la primera Edad del Hierro y las necrópolis de Bencarrón, Gandul y Cruz del Negro como campos de urnas cartagineses de la Segunda Edad del Hierro. Más adelante rectificó estas opiniones, encuadrando definitivamente en la Primera Edad del Hierro tanto a los túmulos como a las necrópolis tipo Cruz del Negro (Maier 1999a: 227).

Finalmente, la excavación de la necrópolis de Setefilla (Lora del Río), que constituyó la culminación de sus investigaciones arqueológicas, permitió a Bonsor subrayar nuevamente la influencia celta en la cultura tartésica, afirmando que sobre la población indígena, impregnada de influencia oriental, se vino a superponer un grupo céltico (Maier 1999a: 278-279).

En definitiva, Bonsor siempre insistió en la importancia que sobre las poblaciones indígenas del Bajo Guadalquivir ejerció no sólo su semitización, sino también la celtización. La influencia de las teorías celtistas llevó a que terminara aceptando la introducción de la incineración en Andalucía por los celtas, pese a que en un principio la había atribuido a los fenicios y libiofenicios. Esta interpretación y la consideración como celta de determinados materiales de las necrópolis de Los Alcores ejercerían una notable influencia sobre posteriores generaciones de arqueólogos, constituyendo durante mucho tiempo algunos de los principales argumentos para postular una presencia celta en el mediodía peninsular (Maier 2007: 333). Sin embargo, la arqueología ha terminado poniendo de relieve el carácter fenicio-tartésico de dichas necrópolis, quedando así desechadas las anteriores tesis celtistas (Maier 2007: 354).

El otro gran investigador de esta etapa, con una labor en buena medida contemporánea a la de Bonsor, fue L. Siret, quien siempre consideró la invasión céltica uno de los acontecimientos determinantes de la Prehistoria peninsular. Para ello se apoyó tanto en los materiales de la provincia de Almería, la región que más intensamente investigó, como en los resultados de los trabajos que Bonsor desarrollaba en Los Alcores.

Ya en su obra Villaricos y Herrerías (1906), Siret afirmó que el inicio de la Edad del Bronce supuso la destrucción del primer imperio fenicio en la Turdetania, resultado de la invasión de belicosas "razas célticas" hacia el siglo XII a. C., que convirtieron a España en el "teatro principal" del "gran duelo" entre Occidente y Oriente. Expulsados del interior de la Turdetania, los fenicios habrían tenido que retirarse a las costas, lo que explicaría la fundación de Gadir y su reducido papel en el desarrollo de la civilización ibérica. Así, para Siret: entre la época neolítica y las conquistas de los cartagineses, la civilización de España fue esencialmente céltica, o lo que es lo mismo, celtibérica (Siret 1906: 417). Posteriormente se produciría la invasión púnica, aunque la población local seguiría sujeta a influencias europeas o célticas, lo que le llevó a distinguir entre sepulturas indígenas, de carácter céltico, y púnicas (Siret 1906: 432).

En trabajos posteriores (Siret 1906-7 y 1909) continuó desarrollando estos argumentos: presencia fenicia a finales del Neolítico, carácter celta de la cultura de El Argar y carácter celto-púnico de las culturas del Hierro andaluzas, aspecto éste último en el que coincidía con Bonsor.

Estos planteamientos le granjearon la crítica de otros prehistoriadores, especialmente de Déchelette, con el que mantuvo una amplia polémica sobre la colonización fenicia y sobre la cronología de la invasión céltica, pues Déchelette (1908) rechazaba la primera y consideraba demasiado antigua la fecha del siglo XII a. C. propuesta por Siret para la segunda.

En su obra Questions de Chronologie et d'Ethnographie ibériques (1913), Siret volvió a posicionarse sobre estas cuestiones, señalando que tras una inmigración ibérica en el Neolítico se produjo la colonización fenicia, seguida de la invasión céltica que debió producirse hacia el 1200 a. C. Posteriormente, la colonización cartaginesa pondría fin a la Edad del Bronce. Siret trató de aportar argumentos arqueológicos que corroboraran sus interpretaciones de carácter etnográfico, por ejemplo a través de la comparación entre la cerámica peninsular de la Edad del Bronce y la centroeuropea (Siret 1913: 82-85).

Ya al final de su vida escribió el artículo "Les premiers celtes en Espagne", que sería publicado poco después de su muerte (1934). En él, insistía en la idea de una invasión céltica en la Península Ibérica, que continuaba datando hacia el 1200 a. C.

Para finalizar el análisis de las figuras de Bonsor y Siret resulta interesante destacar, por su indudable 
interés y por su carácter casi "mítico" dentro de la arqueología hispana, la correspondencia que ambos investigadores mantuvieron entre 1907 y 1910, y que estuvo centrada en la contrastación de sus respectivos resultados (Maier 1999a: 225; 1999b). En relación con nuestro trabajo, y como ya se ha señalado anteriormente, tanto Bonsor como Siret indicaron la presencia de elementos que relacionaban con la civilización celta en las necrópolis tipo Cruz del Negro, constituyéndose así en dos de los precursores del celtismo en España (Maier 1999b).

Otra de las figuras más destacadas de la época fue A. Schulten, cuyos trabajos, entre los que aquí podemos destacar su publicación de la Ora Maritima de Avieno (1922), ejercieron una notable influencia sobre la investigación céltica. Sin embargo, sus investigaciones en el sur peninsular siempre tuvieron como objetivo el descubrimiento de lo que él creía la gran civilización tartésica, y muy especialmente de su mítica capital (Olmos 1991), por lo que apenas prestó atención a los posibles elementos célticos del suroeste, que encajaban mal con el floreciente imperio que debía ser su Tartessos ensoñado. Al considerar que esta gran cultura de Occidente no podía ser autóctona, sino que debía provenir de una emigración desde Oriente, Schulten pasó del origen céltico del nombre de Argantonio a postular un origen tirsenio-anatolio para el pueblo tartésico (Schulten 1945), influido por el debate que venía produciéndose por aquellas fechas sobre el origen de los etruscos (Olmos 1991: 140). En cualquier caso, consideró a los Cempsi celtas o germanos, afirmando que eran vecinos del reino de Tartessos (Schulten 1945: 208).

A caballo entre dos etapas podría considerarse la obra de P. Bosch Gimpera, quien dedicó buena parte de su dilata producción investigadora a plantear ensayos de reconstrucción de los "movimientos célticos". Así, en su gran obra Etnologia de la Península Ibèrica (1932) estableció dos oleadas, una primera en torno al 1000 a. C. representada por los Campos de Urnas y una segunda hacia el 600 a. C. en la que habrían llegado a la Península, entre otros grupos, los célticos y los germanos de Sierra Morena mencionados por Plinio. En relación con la temática que aquí nos ocupa, si bien en su artículo "Los celtas y la civilización céltica en la Península Ibérica" (1921) prestó poca atención a los elementos celtas del sur peninsular, considerando que en el sudeste y en Andalucía la influencia céltica se reduciría a la aparición de algunos tipos aislados (Bosch Gimpera 1921: 295-296), en Etnologia de la Península Ibèrica desarrolló algo más esta cuestión, mencionando las infiltraciones célticas hacia el Guadalquivir que habrían llegado hasta la serranía de Ronda. En cuanto a los oretanos, aunque admitió la existencia de elementos célticos o relacionados con ellos, consideró exagerado considerarlos por ello "celtíberos", como había hecho D’Arbois de Jubainville (Bosch Gimpera 1932).

\section{AUGE Y DECLIVE DE LAS TESIS CELTISTAS}

Tras la Guerra Civil se asiste en España a un avance de las tesis celtistas, que en el caso de la Protohistoria de Andalucía llevarán al entronque de Tartessos con el mundo indoeuropeo. Por otro lado, poco a poco, las fuentes escritas dejarán de ocupar un lugar predominante en la investigación, aunque no será hasta finales de esta etapa cuando desempeñen únicamente un papel complementario y no condicionante del dato arqueológico.

Sin duda la figura más destacada de este periodo, no sólo para la temática que aquí analizamos sino para la arqueología española en general, fue la de M. Almagro Basch. De su ingente obra hemos seleccionado algunos trabajos que tuvieron una especial repercusión en las interpretaciones sobre la presencia céltica en el mediodía peninsular, influyendo en gran cantidad de autores. En
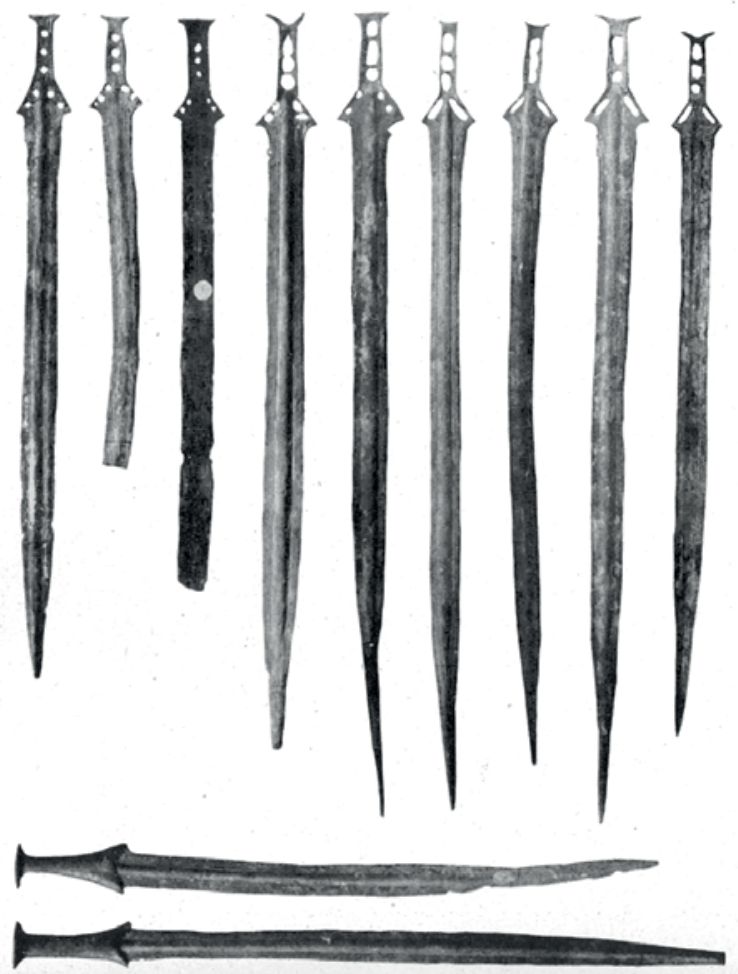

Figura 2. Espadas de lengüeta y de pomo de bronce de la Ría de Huelva (según Almagro Basch 1940) 
primer lugar, la publicación, en 1940, del hallazgo de la Ría de Huelva (Fig. 2). Almagro Basch consideraba que el depósito era contemporáneo, seguramente un cargamento hundido con piezas útiles y piezas rotas para fundir (Almagro Basch 1940: 85). Tras un detallado análisis tipológico de los bronces, concluye un origen europeo para la mayoría de ellos y propone una datación del depósito hacia el 750 a. C. Siguiendo con su razonamiento, señala que representa la llegada y predominio en Huelva de los celtas o de gentes precélticas de origen europeo, que se habrían extendido hacia todo el occidente en un proceso de celtización de las costas occidentales peninsulares al final de la Edad del Bronce (Almagro Basch 1940: 141-143), interpretación que seguirá manteniendo en posteriores publicaciones (Almagro Basch 1975).

La siguiente obra es su famoso estudio sobre "La invasión céltica en España" (1952), dentro de la Historia de España de Menéndez Pidal, en el que plantea también la presencia de poblaciones célticas en el sur de la Península. Por un lado, en la zona almeriense cree detectar materiales atribuibles a los invasores de los Campos de Urnas en las necrópolis de incineración excavadas por Siret (Almagro Basch 1952: 204-206). Por otro, señala que al sur del Tajo los testimonios de esta presencia se limitan a algunos hallazgos de bronces, destacando sin duda el rico depósito de la Ría de Huelva, a los textos literarios, fundamentalmente el periplo de Avieno (Schulten 1922), y a los hallazgos célticos aparecidos en sepulturas de Carmona y Setefilla (Almagro Basch 1952: 225-226). En cualquier caso, estas evidencias probarían para Almagro Basch la existencia hasta época romana de pueblos célticos en esas comarcas, atestiguada por los textos y la toponimia (Almagro Basch 1952: 230 y 246).

Finalmente, en Las estelas decoradas del suroeste peninsular (1966) distingue dos grupos de estelas, las del Grupo I, que se situarían aproximadamente entre el 1000 y el 800 a. C.; y las del Grupo II, entre el 800 a. C. y la plena Edad del Hierro. Siguiendo los textos de Avieno, Herodoto y Herodoro, para Almagro Basch serían estas estelas del Tipo II las que reflejarían la presencia de pueblos célticos invasores, que identifica con los cempsos de las fuentes, diciendo que debieron mezclarse con los cinetes o conios de la etapa anterior, fusión de la que surgirían los pueblos históricos de célticos y lusitanos. Con estas invasiones de los cempsos estaría vinculado el conjunto de armas broncíneas del depósito de la Ría de Huelva. También con estas gentes, o al menos con sus influencias culturales, relaciona las tumbas de incineración de Los Alcores. Estos pueblos invasores célticos debieron ser expulsados, según Almagro Basch, hacia el siglo VI a. C. de las zonas del
Bajo Guadalquivir. En definitiva, mientras las estelas de Tipo I o tipo alemtejano mostrarían la población anterior de los cinetes o conios, las del Tipo II sólo serían propias de la región que dominarían los pueblos cempsos, que habrían llegado hacia el 800 a. C. a estas tierras del suroeste peninsular (Almagro Basch 1966).

En el campo de la lingüística, la figura más relevante durante estos años fue A. Tovar, quien analizó una serie de topónimos considerados célticos (1963). Para este autor debió existir una mezcla entre probables colonos indogermanos e indígenas, señalando que, seguramente, oleadas indogermánicas más antiguas habrían precedido a los celtas (1974). En cualquier caso, Tovar ya advirtió que, a pesar de las referencias literarias sobre celtas en Andalucía, la arqueología aún se había ocupado poco de esta temática (1963: 355).

Desde los trabajos de inicios del siglo $\mathrm{XX}$, uno de los principales apoyos arqueológicos que tenía la presencia céltica en el mediodía peninsular era su vinculación con la práctica de la incineración. Esta interpretación marcó la investigación durante décadas, y no fue superada hasta bien entrados los años 60. Así, en el sudeste autores como E. Cuadrado (1952) sostuvieron que el cambio del rito de inhumación por el de incineración se debió a las influencias culturales y posterior dominación de los invasores celtas, planteando que: del 650-500 se incuba la cultura iberizante del S. E. bajo el signo de lo celta influido por lo clásico (Cuadrado 1952: 260).

No obstante, comenzaron a surgir voces que, sin rechazarla directamente, sí ponían en tela de juicio la asociación celtas - incineración. En este sentido, fueron de gran importancia dos trabajos publicados por J. Maluquer de Motes en 1957 en la revista Zephyrus. En el primero de ellos (1957a), dedicado a un detallado análisis del famoso "bronce Carriazo", Maluquer afirma que la cultura tartésica constituye una simbiosis entre el mundo oriental y el mundo céltico peninsular, idea que desarrollará también en posteriores trabajos (Maluquer de Motes 1970). Así, el autor llega a afirmar que: el contacto de Tartessos con el mundo céltico a nuestro juicio es la premisa necesaria para su propia existencia (1957a: 166). Por su parte, en un segundo artículo Maluquer (1957b) cuestiona la interpretación en términos de diferenciación étnica de la dualidad de rituales funerarios (inhumación e incineración), según la cual existirían dos poblaciones distintas en el sur peninsular: los fenicios (inhumadores) y los celtas (incineradores). Frente a esto, plantea los problemas cronológicos que supone relacionar la incineración con la presencia de pueblos o de tradiciones célticas procedentes de la Meseta (Maluquer de Motes 1957b: 247-248). 
Sin embargo, la vinculación del rito de incineración a la llegada de poblaciones indoeuropeas seguirá presente, como se ve por ejemplo en el trabajo de E. Orta y J. P. Garrido sobre La Joya (1963). Estos autores señalan la presencia, junto con los elementos de indudable carácter mediterráneo, de costumbres funerarias de carácter indoeuropeo, indicando que el rito de la incineración debió llegar por influencia "nórdica". Éste y otros elementos como el hallazgo de cerámica considerada por ellos de tradición hallstáttica en el cercano cabezo de La Esperanza o la existencia de un túmulo en otra altura del Conquero serían para ellos indicativos de la presencia de elementos indoeuropeos, evidenciando que Huelva fue un punto clave en los contactos recíprocos entre mundo mediterráneo y oriental y mundo indoeuropeo y atlántico (Orta y Garrido 1963: 35-36).

La búsqueda de elementos arqueológicos que pudieran vincularse a la presencia de celtas descrita por los escritores de la Antigüedad llevó a una proliferación de materiales clasificados como célticos. Los ejemplos serían numerosos y abarcan desde objetos metálicos como hebillas de cinturón, fíbulas o brazaletes (Fernández Chicarro 1952), a cerámicas (Blanco Freijeiro, Luzón Nogué y Ruiz Mata 1969; Garrido y Orta 1975) y relieves (Blanco Freijeiro 1962). Así, se interpretó la cerámica a mano con decoración incisa y digitada como un indicador de la llegada de gentes procedentes del norte (Blanco Freijeiro, Luzón Nogué y Ruiz Mata 1969). Otros elementos arqueológicos considerados representativos de una presencia indoeuropea fueron las cerámicas de boquique de los estratos inferiores de Carmona, las cerámicas decoradas con incisiones formando bandas horizontales (Garrido y Orta 1975: 261) o los relieves del Cerro Salomón, que Blanco Freijeiro (1962: 4041) consideró de carácter celtizante, agrupándolos con la escultura de la España céltica y de Portugal (1962: 38-39). También J. M. Luzón (1975), en su trabajo sobre las Antigüedades romanas de la provincia de Huelva, señala una serie de elementos que pueden relacionarse con la presencia celta en la región, como el emblema del jabalí en las monedas de Ostur o los nombres de individuo procedentes de la Celtiberia que documenta la epigrafía. Por su parte, en Andalucía oriental, A. Arribas (1969) realizó un intento de identificación y caracterización del componente indoeuropeo que creía presente en el sustrato indígena del Bronce Final.

La obra de J. M. Blázquez Tartessos y los orígenes de la colonización fenicia en Occidente (1968) constituye una buena síntesis de todas las evidencias que en aquellos momentos se solían emplear para postular una presencia céltica en el sur peninsular: textos clásicos (Ora Maritima, Herodoto, Estrabón, Plinio...), toponimia céltica, necrópolis de túmulos de Setefilla, Carmona, Huelva, etc.; no obstante, ya admite la posibilidad de que los enterramientos de Carmona y Setefilla pudieran ser de origen mediterráneo. Y es que por aquellos años comenzaban a proliferar las voces que consideraban que ni la incineración ni la costumbre de enterrar a los muertos bajo túmulos podían ser alegadas como prueba de celtismo, al aparecer también en el mundo mediterráneo.

Sin duda, gran parte de este cambio de orientación se debió a los trabajos desarrollados por M. Pellicer y el Instituto Arqueológico Alemán en la costa mediterránea andaluza, que pusieron de manifiesto la implantación fenicia arcaica en esta zona y contribuyeron decisivamente a romper con las interpretaciones tradicionales que vinculaban el rito de la incineración a la influencia céltica. Por otro lado, es necesario destacar también la intensa revisión a la que se vieron sometidos los materiales de los ajuares de las necrópolis de Los Alcores entre finales de los sesenta e inicios de los ochenta (Maier 2007: 334).

De este modo, se fue produciendo un progresivo retroceso de las tesis celtistas en la Protohistoria de la Península Ibérica, especialmente en los estudios dedicados a Tartessos y el mundo ibérico. Se asiste a un creciente escepticismo a la hora de relacionar elementos de la cultura material con grupos célticos, recayendo el peso de la investigación en el análisis de los componentes orientales, algo por otra parte comprensible en las regiones meridionales. El número de publicaciones arqueológicas que trataban la problemática céltica fue disminuyendo, a la vez que se observan intentos por emplear una terminología más aséptica.

No obstante, hubo excepciones, y autores como Almagro Basch continuaron defendiendo la idea de un sustrato celta para Tartessos (1975). También se comenzó a avanzar durante la década de los 70 en la identificación de los Celtici de la Beturia mencionados por los testimonios clásicos: mientras el trabajo de García Iglesias (1971) realizaba un análisis de la problemática desde la información proporcionada por los escritores greco-latinos y la epigrafía, la excavación en la Sierra de Aracena del poblado de "El Castañuelo" (del Amo 1978) constituyó una de las primeras pruebas materiales de esta presencia céltica.

Por su parte, en un artículo de 1979 dedicado a la proyección de los pueblos de la Meseta sobre Turdetania y el Levante, Blázquez consideraba que, más que de conquista, habría que hablar de filtraciones de bandas o de presencia de elementos culturales meseteños a través del mercenariado y el comercio. Seguía sosteniendo una presencia muy antigua de indoeuropeos en las tierras 
meridionales de la Península, por lo menos desde el 800 a. C., según la cronología de Hawkes para las espadas de la Ría de Huelva; pero al identificar a los celtas con la cultura de La Tène, consideraba que no debían ser calificados de celtas. Por otro lado, mantuvo que la cerámica incisa y digitada presente en poblados como Cerro Salomón fue traída desde la Meseta por gentes indoeuropeas, aunque no en términos de invasión sino de infiltración (Blázquez 1979: 422). Otras pruebas arqueológicas de presencia indoeuropea serían estelas grabadas como las de Carmona, Écija, Setefilla y Córdoba; el nombre de Argantonio; los broches de cinturón de garfios, como el ejemplar de Cástulo y las placas rectangulares con nielados (Blázquez 1979: 425-427). También relacionó con modelos meseteños algunos elementos de las esculturas de Osuna, como la caetra, el escudo oval y el casco de cuero y cimera, considerando que la mayor parte del armamento del sur y levante procedería de la Meseta (Blázquez 1979: 427-428). Finalmente, señalaba otros elementos como la toponimia céltica presente en tierras andaluzas, algunos antropónimos indoeuropeos que podrían indicar la existencia de un numeroso elemento de procedencia celta en las capas superiores de la sociedad turdetana, o el mercenariado (Blázquez 1979: 429-431).

También hay que destacar las intervenciones arqueológicas que realizaron J. M. Blázquez y su equipo en Cástulo (1981). Según los excavadores de este importante centro minero de la Alta Andalucía, los productos cerámicos indígenas presentarían indudables vinculaciones con ámbitos como la Meseta, e incluso con otros transpirenaicos. También en el complejo de construcciones de La Muela, interpretado como santuario, se encontrarían elementos típicos de pueblos que califican, para evitar el uso de términos polémicos como "celtas" o "indoeuropeos", de "continentales” (Blázquez y Valiente 1981).

Otra interesante contribución fue el trabajo de Sáez Fernández (1978), quien señaló la existencia en la Bética de referencias a centuriaciones con nombres de raíz indoeuropea en inscripciones del siglo I d. C. Para este autor, la presencia de elementos célticos en el valle del Guadalquivir constituiría un hecho indudable, confirmado por diversas fuentes literarias, lingüísticas y arqueológicas.

Para finalizar, queremos señalar brevemente un tema de gran complejidad y que ha dado lugar a múltiples interpretaciones: el origen cultural de los mitos de Gárgoris, Habis y Gerión. Las opiniones al respecto son abundantes y dispares, por lo que no pueden quedar recogidas todas aquí. Como muestra, cabe señalar que Maluquer (1970) ha considerado el mito de Gárgoris y Habis oriental y preindoeuropeo, mientras el de Gerión sería ya indoeuropeo; Bermejo (1978) atribuye el mito de Gárgoris y Habis al "complejo cultural tartésico"; y AlmagroGorbea (1996: 53-54) señala que el triplismo del mito de Gerión apuntaría a un origen indoeuropeo muy antiguo.

\section{ENTRE HALLAZGOS LINGÜÍSTICOS Y OLVIDO ARQUEOLÓGICO: ESTADO ACTUAL DE LA PROBLEMÁTICA}

En las últimas dos décadas la cuestión de la presencia "céltica" en el mediodía peninsular ha pasado a ocupar un papel muy marginal, cuando no inexistente, en la mayor parte de las agendas investigadoras arqueológicas. Como ya se señaló al inicio, la Beturia Céltica constituye una notable excepción, ya que su estudio viene experimentando un gran desarrollo desde finales de la década de los 80 del siglo XX, sobre todo gracias a los trabajos de L. Berrocal Rangel (1992 y 2005). Las intervenciones llevadas a cabo en poblados protohistóricos del sur de Extremadura como Castrejón de Capote, y también en el norte de la provincia de Huelva, han permitido caracterizar la cultura material de estos grupos célticos, que se pone en relación con la de poblaciones asentadas en la Meseta (Berrocal Rangel 1992 y 2001; Pérez Macías 1996; Rodríguez Díaz 1993).

Por el contrario, en el resto de las tierras del sur peninsular la temática ocupa un papel muy secundario, aunque evidentemente existen excepciones, como muestran los estudios de Pérez Vilatela. Este autor, realizando una interpretación ciertamente discutible de las fuentes literarias y los datos lingüísticos, llega a afirmar que: la Andalucía occidental prerromana es básicamente celta y también ciertas zonas de la central (Pérez Vilatela 1994: 76).

Sin lugar a dudas, el campo que mayores novedades ha aportado al conocimiento de la problemática "céltica" ha sido la lingüística. Sin obviar las contribuciones que vienen realizando los análisis de toponimia antigua (Díez Asensio 1994; Untermann 2001; Villar 2000), creemos que el hecho más destacado de las últimas décadas en este campo es el descubrimiento por J. A. Correa (1989) de posibles antropónimos celtas en las inscripciones del suroeste, hallazgo que ha recibido un fuerte respaldo con la reciente publicación por Almagro-Gorbea (2002 y 2004) del teónimo Niethos. Gracias a los trabajos de Correa, autores como J. Untermann (1997: 165) consideran que no es descartable que la lengua de las inscripciones tartésicas perteneciera a la familia de lenguas indoeuropeas. Por su parte, J. de Hoz (1995) habla de una colonización lingüística céltica en dos sentidos: la ocupación de territorios que habrían adquirido un color etnográfico unitario y la ocupación de puntos aislados. 
En todo caso, considera que estos datos toponímicos o antroponímicos sobre indoeuropeos en la Bética no son proyectables a época tartésica (de Hoz 1995: 593).

Más controvertido pero también innovador resulta el trabajo de F. Villar (2000), quien considera carente de fundamento cualquier intento de establecer una división entre un área indoeuropea y otra no indoeuropea en la Hispania prerromana. Así, distingue seis estratos “(étnico-) lingüísticos" en la región meridional, atribuyendo una mayor antigüedad a los tres primeros: indoeuropeo meridional-ibero-pirenaico; tartesio; lengua de las inscripciones suroccidentales (que contiene material indoeuropeo); lengua o lenguas de tuci, -igi y la final -t; celta; e ibero (Villar 2000: 423).

Finalmente, resulta obligado destacar la reciente publicación por M. Almagro-Gorbea (2002 y 2004) de un excepcional grafito procedente del ambiento portuario de la antigua Onuba (Huelva), que documenta la primera divinidad tartesia de nombre conocido: Niethos (Fig. 3). El hecho de que, muy probablemente, se trate de una divinidad de tipo celta, sumado a su temprana datación (hacia el 590-570/560 a. C.), abre nuevas perspectivas, pero también nuevos interrogantes, sobre la discutida presencia céltica en el sur peninsular.

La revisión de las fuentes escritas también ha aportado trabajos interesantes, como la obra de A. Capalvo (1996), una de las más polémicas de los últimos años. Retomando una teoría ya expuesta en su día por D'Arbois de Jubainville (1893-94), este autor localiza en la Bética las ciudades de Munda y Certima e identifica la "ultima Celtiberia" con la "Celtiberia Ulterior", situando ésta en las actuales provincias de Málaga y Cádiz; interpretación que, como era de esperar, no ha quedado exenta de críticas. En todo caso, y como bien ha indicado F. Burillo (1998: 36-37), la propuesta de Capalvo, de aceptarse, implicaría un significado del término de celtíbero en su sentido más amplio: celtas en Iberia.

Pasando ya al ámbito más estrictamente arqueológico, no puede dejar de sorprender el escaso eco que han encontrado los notables avances de la lingüística entre los arqueólogos, siendo muy escasas las publicaciones que tratan desde una perspectiva arqueológica aspectos relacionados con la presencia céltica. En primer lugar, hay que citar la obra de Lenerz-de Wilde (1991), que sigue la línea de la investigación alemana de identificar a los celtas con la cultura material del Hallstatt final y La Tène. De su análisis de los hallazgos con carácter lateniense en Iberia destaca su frecuente presencia en el sudeste hispano desde el siglo IV a. C., que la autora pone en relación, entre otros motivos, con la presencia en estas regiones de artesanos y posteriormente de tropas mercenarias célticas.

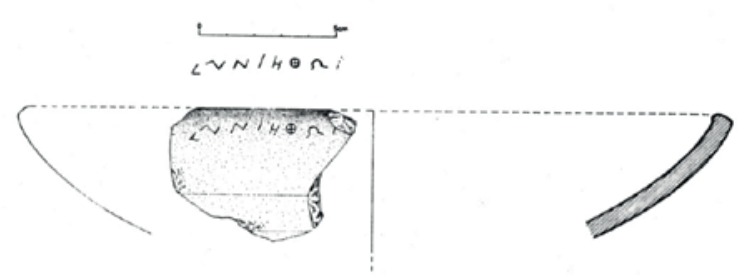

Figura 3. Cuenco samio hallado en Huelva con el grafito ...]

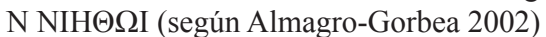

También resultan interesantes una serie de hallazgos que indican la presencia de elementos celtibéricos en época tardía. Por un lado, la publicación por Remesal (1999) de una tésera de hospitalidad de carácter celtibérico procedente de la Mesa del Almendro, cercana a la Mesa de Setefilla. Por otro, la presencia hacia finales del siglo II e inicios del I a. C. de monedas procedentes de cecas celtibéricas en ámbitos mineros del sureste y sur peninsular (Burillo 1998: 305; 309-312); un ejemplo serían los datos aportados por las monedas del poblado minero de La Loba (Fuenteobejuna, Córdoba), que sugieren la presencia de mineros procedentes de la Celtiberia (Blázquez, Domergue y Sillières 2002).

Los trabajos más recientes, si bien señalan en todo momento la presencia "céltica" en el mediodía peninsular, no profundizan en el estudio de este componente. La sugerente línea de investigación sobre identidades étnicas en los pueblos prerromanos de la Baja Andalucía que se viene desarrollando en el Departamento de Prehistoria y Arqueología de la Universidad de Sevilla resalta la convivencia de distintos grupos étnicos (turdetanos, túrdulos, bástulo-púnicos, célticos, etc.) en un mismo territorio (Escacena Carrasco 1992; Escacena Carrasco y Belén Deamos 1998; Ferrer Albelda y García Fernández 2002; Chaves Tristán et al. 2006; García Fernández 2007). Pero entre estos distintos componentes, el "céltico" es sin duda uno de los menos conocidos, en parte por la gran dificultad que ofrece su identificación y estudio, en parte porque el interés se viene centrando en los elementos orientales y en el estudio de los turdetanos.

\section{REFLEXIONES FINALES}

La presencia en el sur peninsular de poblaciones que podríamos denominar como "célticas" constituye una realidad difícil de cuestionar a la luz de la documentación actual, si bien aún estamos lejos de dilucidar su 
verdadero carácter y alcance. Los datos más antiguos (fuentes clásicas, antropónimos en las inscripciones del suroeste, teónimo Niethos, etc.), si bien tomados individualmente presentan cierta incertidumbre, puestos en conjunto podrían confirmar las noticias de Herodoto sobre la presencia de "celtas" más allá de las Columnas de Hércules, reforzando la idea de una celtización considerablemente más antigua a los movimientos descritos por Plinio (Almagro-Gorbea 2002: 57-58 y 2005: 32; Untermann 2001: 197). Esto no excluiría en ningún momento procesos posteriores como la imposición de élites guerreras o el mercenariado (Almagro-Gorbea 2001: 110111 y 2005: 34), que muestran que la presencia de elementos "célticos" fue un fenómeno con características dispares en el tiempo y en el espacio. Indudablemente, se trata de un asunto de gran interés, cuya verdadera potencialidad creemos que aún no ha sido suficientemente advertida, ya que puede arrojar nueva luz sobre el propio concepto de "celtas" a una escala europea.

En cualquier caso, es necesario finalizar recordando que, lejos de las visiones esencialistas que establecían la correspondencia etnia-cultura material y definían a los grupos étnicos como entes homogéneos y estáticos, la realidad paleoetnológica de la Hispania Antigua debió aproximarse mucho más a un complejo y dinámico "mosaico étnico" que a los espacios homogéneos con fronteras claramente definidas que son habitualmente utilizados para expresar los supuestos territorios étnicos ${ }^{1}$. En este sentido, cabe destacar que la propia celtización de la Península Ibérica es concebida actualmente como un proceso acumulativo "en mosaico", hecho que explicaría la personalidad y diversidad de sus distintas poblaciones “célticas" (Almagro-Gorbea 2001: 109-110 y 2005: 37).

\section{AGRADECIMIENTOS}

Debo agradecer a los Profs. Martín Almagro Gorbea, Gonzalo Ruiz Zapatero y Mariano Torres Ortiz (Universidad Complutense de Madrid), Luis Berrocal Rangel (Universidad Autónoma de Madrid) y Francisco José García Fernández (Universidad de Sevilla), así como al Dr. Jorge Maier Allende (Real Academia de la Historia) los valiosos comentarios, referencias y opiniones que me han aportado en la elaboración y redacción de este trabajo. Evidentemente, todas las opiniones $\mathrm{y}$, por supuesto, todos los errores que pueda haber son de mi única responsabilidad.

1. Para una revisión en profundidad de las complejas y a menudo problemáticas relaciones entre arqueología y etnicidad véase Fernández Götz 2008.

\section{BIBLIOGRAFÍA}

ALMAGRO BASCH, M. (1940): "El hallazgo de la ría de Huelva y el final de la Edad del Bronce en el Occidente de Europa", Ampurias II: 85-143.

ALMAGRO BASCH, M. (1952): "La invasión céltica en España”, en R. Menéndez Pidal (ed.), Historia de España I (2): 1-278. Espasa-Calpe, Madrid.

ALMAGRO BASCH, M. (1966): Las estelas decoradas del suroeste peninsular. CSIC, Madrid.

ALMAGRO BASCH, M. (1975): "Depósito de bronces de la ría de Huelva", en M. Almagro Basch et al., Huelva: prehistoria y antigüedad: 213-220. Editora Nacional, Madrid.

ALMAGRO-GORBEA, M. (1996): Ideología y poder en Tartessos y el mundo ibérico. Real Academia de la Historia, Madrid.

ALMAGRO-GORBEA, M. (2001): "Los Celtas en la Península Ibérica”, en M. Almagro-Gorbea, Ma Mariné y J. R. Álvarez Sanchís (eds.), Celtas y Vettones: 94-113. Diputación Provincial de Ávila, Ávila.

ALMAGRO-GORBEA, M. (2002): "Una probable divinidad tartésica identificada: Niethos/Netos”, $\mathrm{Pa}$ laeohispanica 2: 37-70.

ALMAGRO-GORBEA, M. (2004): "NIETHOS-Néit: The earliest documented Celtic god (c. 575 BC) and the Atlantic relationships between Iberia and Ireland", en H. Roche et al. (eds.), From Megaliths to Metal: Essays in Honour of George Eogan: 200208. Oxbow Books, Oxford.

ALMAGRO-GORBEA, M. (2005): "Los Celtas en la Península Ibérica", en A. Jimeno Martínez (ed.), Celtiberos. Tras la estela de Numancia: 29-37. Diputación de Soria, Soria.

D'ARBOIS DE JUBAINVILLE, H. (1893-94): "Les Celtes en Espagne", Revue Celtique 14: 357-395; 15: 1-61.

ARRIBAS, A. (1969): “La Andalucía oriental y el problema de Tartessos", Tartessos y sus problemas. V Symposium Internacional de Prehistoria Peninsular, Jerez de la Frontera, 1968: 199-202. Universidad de Barcelona.

BERMEJO BARRERA, J. C. (1978): “La función real en la mitología tartésica. Gárgoris, Habis y Aristeo", Habis 9: 215-232.

BERROCAL RANGEL, L. (1992): Los pueblos célticos del Suroeste de la Península Ibérica. Complutum Extra 2, Madrid.

BERROCAL RANGEL, L. (2001): “Aproximaciones metodológicas a la demografía protohistórica: el siglo IV a. C. en el Suroeste", en L. Berrocal y P. Gardes (eds.), Entre celtas e íberos: las poblaciones 
protohistóricas de las Galias e Hispania: 89-105. Real Academia de la Historia, Madrid.

BERROCAL RANGEL, L. (2005): "The Celts of the Southwestern Iberian Peninsula", e-Keltoi 6, The Celts in the Iberian Peninsula: $481-496$ (http:// www.uwm.edu/Dept/celtic/ekeltoi/).

BLANCO FREIJEIRO, A. (1962): “Antigüedades de Riotinto", Zephyrus XIII: 31-46.

BLANCO FREIJEIRO, A.; LUZÓN NOGUÉ, J. M. y RUIZ MATA, D. (1969): "Panorama tartésico en Andalucía occidental”, Tartessos y sus problemas. V Symposium Internacional de Prehistoria Peninsular, Jerez de la Frontera, 1968: 119-162. Universidad de Barcelona.

BLÁZQUEZ, J. M. (1968): Tartessos y los orígenes de la colonización fenicia en Occidente. Universidad de Salamanca.

BLÁZQUEZ, J. M. (1979): "La proyección de los pueblos de la Meseta sobre Turdetania y el Levante ibérico en el primer milenio a. C.", Actas del II Coloquio sobre lenguas y culturas prerromanas de la Península Ibérica (Tübingen 1976): 421-434. Ediciones Universidad de Salamanca.

BLÁZQUEZ, J. M. y VALIENTE, J. (1981): Cástulo III (EAE 117). Madrid.

BLÁZQUEZ, J. M.; DOMERGUE, C. y PIERRE SILLIÈRES (eds.) (2002): La Loba (Fuenteobejuna, province de Cordoue, Espagne): la mine et le village minier antiques. Institut Ausonius, Burdeos.

BONSOR SAINT MARTIN, J. (1899): "Les colonies agricoles prerromaines de la valle du Betis", Revue Archeologique XXXV.

BOSCH GIMPERA, P. (1921): "Los celtas y la civilización céltica en la Península Ibérica", Boletín de la Sociedad Española de Excursiones 29: 248-301.

BOSCH GIMPERA, P. (1932): Etnologia de la Península Ibèrica. Editorial Alpha, Barcelona.

BURILLO MOZOTA, F. (1998): Los celtíberos: etnias y estados. Crítica, Barcelona.

CAPALVO, A. (1996): Celtiberia: un estudio de fuentes literarias antiguas. Institución Fernando el Católico, Zaragoza.

CARO, R. (1634): Antigüedades y principado de la ilustrísima ciudad de Sevilla y Chorografía de su convento jurídico o antigua chancillería. Sevilla.

CHAVES TRISTÁN, F.; GARCÍA FERNÁNDEZ, F. J. y FERRER ALBELDA, E. (2006): "Relaciones interétnicas e identidades culturales en Turdetania (siglos II a. C. - I d. C.)", L'Africa romana XVI, Rabat 2004: 813-828. Roma.

CORREA, J. A. (1989): "Posibles antropónimos en las inscripciones en escritura del S.O. (o tartesia)", $\mathrm{Ve}$ leia 6: 243-252.
CUADRADO, E. (1952): "Las tumbas ibéricas de empedrado tumular y la celtización del Sudeste", II Congreso Nacional de Arqueología (Madrid 1951): 247-267. Zaragoza.

DÉCHELETTE, J. (1908): "Essai sur la chronologie préhistorique de la Péninsule ibérique", Revue Archeologique XII: 219-265; 390-415.

DEL AMO, M. (1978): "El Castañuelo. Un poblado céltico en la provincia de Huelva", Huelva Arqueológica IV: 299-340.

DÍEZ ASENSIO, J. (1994): "Presencia indoeuropea en la Bética prerromana: Testimonios toponomásticos antiguos", Actas del II Congreso de Historia de Andalucía. Córdoba, 1991: 77-88. Córdoba.

ESCACENA CARRASCO, J. L. (1992): "Indicadores étnicos en la Andalucía prerromana", Spal 1: 321343. http://dx.doi.org/10.12795/spal.1992.i1.16

ESCACENA CARRASCO, J. L. y BELÉN DEAMOS, M. (1998): "Pre-Roman Turdetania", en S. Keay (ed.), The archaeology of early Roman Baetica. Journal of Roman Archaeology: 23-37.

FERNÁNDEZ CHICARRO, C. (1952): “Objetos de origen céltico en el Museo Arqueológico de Sevilla", II Congreso Nacional de Arqueología (Madrid 1951): 321-326. Zaragoza.

FERNÁNDEZ GÖTZ, M. A. (2008): La construcción arqueológica de la etnicidad. Serie Keltia 42. Editorial Toxosoutos, Noia (A Coruña).

FERRER ALBELDA, E. y GARCÍA FERNÁNDEZ, F. J. (2002): "Turdetania y turdetanos: contribución a una problemática historiográfica y arqueológica", Mainake XXIV: 133-151.

FITA, F. (1897): "Los Callenses Aeneanici del Arahal y de Montellano", Boletín de la Real Academia de la Historia XXXI: 381-390.

GARCÍA FERNÁNDEZ, F. J. (2007): "Etnología y etnias de la Turdetania en época prerromana", $\mathrm{Cu}$ PAUAM 33: 117-143.

GARCÍA IGLESIAS, L. (1971): "La Beturia, un problema geográfico de la Hispania Antigua”, Archivo Español de Arqueología 44: 86-108.

GARRIDO, J. P. y ORTA, E. (1975): “El problema de Tartessos: una interpretación arqueológica", en M. Almagro Basch et al., Huelva: prehistoria y antigüedad: 249-263. Editora Nacional, Madrid.

GÓNGORA Y MARTÍNEZ, M. (1868): Antigüedades prehistóricas de Andalucía, monumentos, inscripciones, armas, utensilios y otros importantes objetos pertenecientes a los tiempos más remotos de su población. Madrid.

GONZÁLEZ RUIBAL, A. (2005): “¿Para qué sirven los celtas?”, en G. Ruiz Zapatero (ed.), “Un círculo 
de lectores: Miradas sobre los celtas del NO. de la Península Ibérica", Complutum 16: 181-185.

HOZ, JAVIER DE (1995): “Tartesio, fenicio y céltico 25 años después", Tartessos: 25 años después, 1968-1993: 591-607. Jerez de la Frontera.

HÜBNER, E. (1893): Monumenta Linguae Ibericae. Berolini, Berlín.

VON HUMBOLDT, W. (1821): Prüfung der Untersuchungen über die Urbewohner Hispaniens vermittelst der Vaskischen Sprache. Ferdinand Dümmler Verlag, Berlín.

KIEPERT, H. (1865): "Beitrag zur alten Ethnographie der iberischen Halbinsel". Monatsberichte der Königlich Preußischen Akademie der Wissenschaften zu Berlin 1864: 143-165. Berlín.

LENERZ-DE WILDE, M. (1991): Iberia Celtica: Archäologische Zeugnisse keltischer Kultur auf der Pyrenäenhalbinsel. Franz Steiner Verlag, Stuttgart.

LUZÓN NOGUÉ, J. M. (1975): “Antigüedades romanas en la provincia de Huelva”, en M. Almagro Basch et al., Huelva: prehistoria y antigüedad: 271320. Editora Nacional, Madrid.

MAIER, J. (1999a): Jorge Bonsor (1855-1930): un académico correspondiente de la Real Academia de la Historia y la Arqueología Española. Real Academia de la Historia, Madrid.

MAIER, J. (1999b): Epistolario de Jorge Bonsor (18861930). Real Academia de la Historia, Madrid.

MAIER, J. (2007): "Las necrópolis protohistóricas de Los Alcores: relectura de la tradición arqueológica", en M. Bendala Galán y Ma Belén Deamos (dir.), El nacimiento de la ciudad: la Carmona protohistórica: 331-363. Universidad de Sevilla - Ayuntamiento de Carmona, Carmona.

MALUQUER DE MOTES, J. (1957a): "De metalurgia tartesia: el bronce Carriazo", Zephyrus VIII: 157-168.

MALUQUER DE MOTES, J. (1957b): “Un interesante lote de bronces, hallado en el castro de Sanchorreja (Ávila)", Zephyrus VIII: 241-256.

MALUQUER DE MOTES, J. (1970): Tartessos. La ciudad sin historia. Ediciones Destino, Barcelona.

MITJANA, R. (1847): Memoria sobre el Templo Druida hallado en las cercanías de la Ciudad de Antequera. Málaga.

MURGUÍA, M. (1858): "Monumentos celtas descubiertos en la provincia de Granada", Museo Universal II: 67-68.

OLMOS, R. (1991): “A. Schulten y la historiografía sobre Tartessos en la primera mitad del siglo XX", en J. Arce y R. Olmos (coord.), Historiografía de la Arqueología y de la Historia Antigua en España (siglos XVIII-XX). Congreso Internacional, Madrid, 13-16 diciembre 1988: 135-144.

ORTA, E. Y GARRIDO, J. P. (1963): "La tumba orientalizante de 'La Joya', Huelva", Trabajos de Prehistoria 11: 1-36.

PASCUAL BAREA, J. (2004): “Callet y Callenses Aeneanici (Montellano, Morón): la ceca, el topónimo, el territorio y los oppida", Anejos de AEspA XXXIII: 25-31.

PÉREZ MACÍAS, J. A. (1996): "La transición a la Edad del Hierro en el suroeste peninsular: el problema de los Celtici”, Spal 5: 101-114. http://dx.doi. org/10.12795/spal.1996.i5.05

PÉREZ QUINTERO, M. I. (1794): La Beturia vindicada ó ilustración crítica de su tierra, con la noticia de algunas de sus ciudades e islas. Sevilla.

PÉREZ VILATELA, L. (1994): "Perspectiva diacrónica de los Celtas en la Bética", Actas del II Congreso de Historia de Andalucía. Córdoba, 1991: 6976. Córdoba.

REMESAL RODRÍGUEZ, J. (1999): “En torno a una nueva tésera de hospitalidad", en F. Villar y F. Beltrán (eds.), Pueblos, lenguas y escrituras en la Hispania prerromana. Actas del VII Coloquio sobre lenguas y culturas paleohispánicas (Zaragoza 1997): 595-603. Salamanca.

RODRÍGUEZ DÍAZ, A. (1993): "Sobre la periferia turdetana y la configuración diversa de la Beturia prerromana. Célticos y Túrdulos en el Guadiana Medio", Spal 2: 243-267. http://dx.doi.org/10.12795/ spal.1993.i2.10

RUIZ ZAPATERO, G. (1993): "El concepto de Celtas en la Prehistoria europea y española", en M. Almagro-Gorbea y G. Ruiz Zapatero (eds.), Los Celtas: Hispania y Europa: 23-62. Universidad Complutense, Madrid.

RUIZ ZAPATERO, G. (2001): “¿Quiénes fueron los celtas? Disipando la niebla: mitología de un collage histórico", en M. Almagro-Gorbea, Ma Mariné y J. R. Álvarez Sanchís (eds.), Celtas y Vettones: 72-91. Diputación Provincial de Ávila, Ávila.

SÁEZ FERNÁNDEZ, P. (1978): "Las centurias de la Bética", Habis 9: 255-271.

SCHULTEN, A. (1922): Avieno. Ora Maritima (Periplo Massaliota del siglo VI a. de J.C.). Fontes Hispaniae Antiquae I. Universidad de Barcelona, Barcelona.

SCHULTEN, A. (1945): Tartessos. Espasa Calpe, Madrid.

SIRET, L. (1906): Villaricos y Herrerías. Antigüedades púnicas, romanas, visigóticas y árabes. Memorias de la Real Academia de la Historia 14: 380-478. Madrid. 
SIRET, L. (1906-7): “Orientaux et Occidentaux en Espagne aux temps préhistoriques", Revue des Questions Scientifiques 3, Ser. 10: 529-582; 3, Ser. 11: 219-269.

SIRET, L. (1909): "Tyriens et celtes en Espagne", Revue des Questions Scientifiques 3, Ser. 15: 51-63.

SIRET, L. (1913): Questions de Chronologie et d'Ethnographie ibériques. Tome I: De la fin du Quaternaire à la fin du Bronze. París.

SIRET, L. (1934): "Les premiers celtes en Espagne", Anuario del Cuerpo Facultativo de Archiveros, Bibliotecarios y Arqueólogos 1: 85-103.
TOVAR, A. (1963): "Les Celtes en Bétique", Études Celtiques 10: 354-373.

TOVAR, A. (1974): Iberische Landeskunde. Band 1: Baetica. Baden-Baden.

UNTERMANN, J. (1997): Die tartessischen, keltiberischen und lusitanischen Inschriften (Monumenta Linguarum Hispanicarum IV). Wiesbaden.

UNTERMANN, J. (2001): "La toponimia antigua como fuente de las lenguas hispano-celtas", $\mathrm{Pa}$ laeohispanica 1: 187-218.

VILLAR, F. (2000): Indoeuropeos y no indoeuropeos en la Hispania prerromana. Ediciones Universidad de Salamanca.

FECHA DE ENTRADA: 18-09-2007

FECHA DE ACEPTACIÓN: 19-11-2008 